\author{
자망에 대한 대게 암컷의 망목 선택성 \\ 박창두 ${ }^{\star}$ - 안희 춘' - 조삼광 - 배봉성 ${ }^{2}$ 박해훈 ${ }^{2}$ - 배재현 $\cdot$ 김현영 \\ 국립수산과학원 서해수산연구소 자원환경과, ${ }^{1}$ 국립수산과학원 수산공학과, \\ 국립수산과학원 동해수산연구소 자원환경과
}

\title{
Size selectivity of gill net for female snow crab, Chionoecetes opilio
}

\author{
Chang-Doo PARK*, Heui-Chun AN ${ }^{1}$, Sam-Kwang Cho, Bong-Seong BAE ${ }^{2}$, Hae-Hoon PARK², \\ Jae-Hyun BAE ${ }^{1}$ and Hyun-Young KIM \\ Fisheries Resources Division, West Sea Fisheries Institute, NFRDI, Incheon 400-420, Korea \\ ${ }^{1}$ Fisheries Engineering Division, National Fisheries Research \& Development Institute,
}

Busan 619-902, Korea

${ }^{2}$ Fisheries Resources Division, East Sea Fisheries Institute, NFRDI, Gangwon-do 210-861, Korea

A series of fishing experiments was carried out in the eastern coastal waters of Korea from January, 2002 to March, 2003, using gill nets of different mesh sizes ( $m=180,210,240,270$ and $300 \mathrm{~mm})$ to determine the size selectivity of gill net for female snow crab, Chionoecetes opilio. The catch of experimental gears was mostly snow crab (97\%), Chionoecetes opilio. The maximum carapace length $(R L)$ of each female snow crab caught in the fishing experiments was measured. The master selection curve was estimated by applying the extended Kitahara's method. The selection curve showed that the gill nets of larger mesh size allowed more female crabs of small carapace size to escape. The optimum values of $R L / m$ for 1.0 of retention probability was 0.563 and $R L / m$ was estimated to be $0.249,0.290,0.319,0.344$ and 0.367 when the retention probability were $0.1,0.2,0.3,0.4$ and 0.5 , respectively.

Key words : Chionoecetes opilio, Snow crab, Gill net, Selectivity, Selection curve, Kitahara’s method
서 론
양 캐나다 연안 등에 분포하고 있으며, 서식 수
대 게(Snow crab, Chionoecetes opilio)는 우리나 심은 $50-600 \mathrm{~m}$, 저질은 니질 또는 사니질, 서식
라 동해안을 비롯하여 일본의 서해안 및 동북해 수온은 $0-5{ }^{\circ} \mathrm{C}$ 로 알려져 있다(Miyake, 1983;
안, 베 링해, 오호츠크해, 알래스카 연 안 북대서
$\mathrm{Lim}, 2001)$. 그리고 대게는 탈피를 통하여 성장

\footnotetext{
*Corresponding author: cdpark1@nfrdi.go.kr, Tel. +82-32-745-0570, Fax.+82-32-745-0569
} 
하는 갑각류의 일종으로써 대게 암컷(이하 암게 로 표현)이 수컷(이하 수게로 표현)에 비하여 개 체 크기가 상대적으로 작은 생물학적 특징을 가 지 고있다(Yamasaki, 1994).

대게는 고가로 유통되므로 산업적 측면에서 매우 중요한 어종이며 대게를 어획하는 각국에 서는 자원의 지속적 유호이용을 위하여 어획량 규제(TAC 제도), 포획금지체장 설정, 금어기 설 정 등의 조치를 취하고 있고, 일본의 일부 지역 을 제외한 모든 국가에서는 암게의 포획을 금지 하고 있다(Yamasaki, 1994; Xu and Millar, 1993). 우리나라에서도 대게 자원의 보호를 위하여 수 산자원 보호령으로 암게 포획금지, 금어기 설정, 포획금지체 장 $(9 \mathrm{~cm}$ 이하) 설정, 어 구의 망목크기 제 한자망은 $240 \mathrm{~mm}$, 통 발은 $150 \mathrm{~mm}$ 이 하 사용 금지) 등의 규제를 두고 있다.

우리나라의 어업별 대게 어획량 비율을 보면, 자망이 어획량의 $87.3 \%$ 를 점하고 있고, 통발이 $11.6 \%$ 를 차지하고 있다(2007년 어업생산통계). 이와같은 어업별 어획비 중은 주로통발 또는 저 인 망을 사용하여 대게를 어 획하는 외 국의 어업 과는 차이가 있다(Yamasaki, 1994; Xu and Millar, 1993; Conan and Comeau, 1986). 따라서 우리나 라 연안에 서식하는 대 게 자원의 지속적 이용을 위해서는 어획 비중이 높은 자망에 의한 어업관 리가 매우 중요하다. 특히, 재생산에 기여하는 암게의 혼획을 감소시키고 상품성이 있는 적정 량의 대형 수게만을 선 택적으로 어획하는 것이 필 요하다.

본 연구에서는 자망에 대한 암게의 망목선택 성을 구명하기 위하여 망목의 크기를 다르게 하 여 제작한 대게자망으로경북 죽변항 주변 수역 에서 시 험조업을 행하고 자망의 망목 크기에 따 른 암게의 망목선택성을 분석하였다.

\section{재료 및 방법}

\section{조업시험의 개요}

우리나라 대게 자망어업은 주로 동해안 연안
수역에서 행해지고 있으며, 이들 어선들의 조업 수심은 약 $150-400 \mathrm{~m}$ 이다. 자망 어구는 지역에 따라 구성을 다소다르게 하여 사용하기도 하나, 대부분 은 나일론 단일섬유(monofilament)로 제 작된 길이 200 장대 $(1$ 필, $300 \mathrm{~m})$ 의 망지로 뜸줄약 $80 \mathrm{~m}$, 발줄 약 $90-100 \mathrm{~m}$ 의 규모로 완성어 구 1 폭 을 제 작하는데, 이 때 재 질이 폴리프로필 렌인 뜸 줄에는 뜸을 달지 않으며 발줄은 납침자로 침강 력을 준다. 어선 1 척은 대게 자망 그물 $15-30$ 폭 을 1 조(틀)로 하여 5-6조의 어구를 분산투망하 는 방법으로 조업하며, 어구의 침지 일 수는 기상 상태 등의 여건에 따라7 - 30일 정 도이다.

본 연구에서 사용한 대게 자망의 망목크기 $m(\mathrm{~mm})$ 은 5 종류(각각 $180,210,240,270,300 \mathrm{~mm}$ ) 를 사용하였다. 망사직 경 $d(\mathrm{~mm})$ 는 본 시 험을 위 하여 별로로 제 작하는 것 없이 상업용으로 제작 판매되는 망지를 그대로 활용하였으며 망목크 기 증가에 따른 망사 직경은 각각 경 심 4 회 $(\phi=$ $0.331), 5$ 호$(\phi=0.370), 6$ 호 $(\phi=0.405), 7$ 호 $(\phi=$ $0.438), 8$ 호 $(\phi=0.468)$ 이었다. 시험 어구 1 틀은 각 망목크기별로 4 폭씩 총 20 폭을 망목크기 순 으로 반복배치하여 구성하였다. 시험 조업은 죽 변항 소속의 제 3 광웅호(7.93톤)와 제99 성광호 (6.33톤)를 용선하여 사용하였다. 시험 조업은 2002년 1 월 부터 2003년 3 월 사이에 각 선 박별 6 회, 총 12 회 수행하였으며, 침지 일수는 $10-25$ 일이었다.

시험어 구에 어획된 대게는 망목 크기별로 분 류하여 갑폭 $C W(\mathrm{~mm})$, 최대갑장 $R L(\mathrm{~mm})$, 갑장 $C L(\mathrm{~mm})$, 집게 발(chela) 높이 $C h(\mathrm{~mm})$ 등을 디지 털 켈리퍼스를 이용하여 $0.1 \mathrm{~mm}$ 단위로 측정하 였다(Park et al., 2003). 대게 의 경우, 갑장의 정의 (Jadamec et al., 1999)는 다양하나, 본 연구에서 는 갑(甲)의 중앙 후부를 기점으로 안와 후부까지의 수평 거리를 갑장 $C L$, 중앙 전면의 돌출부 끝부 분까지의 수평거리를 최대갑장 $R L$ 으로 표현하 였다(Park et al., 2003). 대게 의 경우, 생물학적 대 표 체장으로 갑폭이 많이 사용되고 있으나, 본 연 
구에서는 수산자원 보호령의 갑장기준을 고려하 여 대표 체장을 최대갑장으로 나타내었다.

\section{망목 선택성 곡선 추정법}

자망의 망목선 택성 추정방법에 는 Ishida 방법 (Ishida, 1962), Holt 방법 (FAO, 1992), Kitahara 방 법(Kitahara, 1968), SELECT 모델을 적용하는 방 법(Park et. al., 2004 ; Millar and Walsh, 1992) 등 이 사용되고 있다. 본 연구에서는 망목선택성 곡 선을 하나의 Master Curve로 나타낼 수 있는 Kitahara 방법(Fujimori et al., 1996; Cho et al., 2000; Park et al., 2003)을 적 용하여 자망에 대한 암게의 망목선택성을 해석하었다.

\section{결과 및 고찰}

시험조업 결과, 대게가 전체 어획 개체수의 $97 \%$ 를 차지하었고 고무꺽정이, 고동류 등이 일 부 혼획되는 것으로 나타났다. 대게의 어획 개체 수 중에서 수게와 암게의 비율은 각각 2,351 마리 $(56.7 \%), 1,795$ 마리(43.3\%)였다.

\section{갑장과 갑폭과의 관계}

어획시 험 결과로부터 얻어진 암게의 갑폭 $C W(\mathrm{~mm})$, 최 대갑장 $R L(\mathrm{~mm})$, 갑장 $C L(\mathrm{~mm})$, 체 고 $B H(\mathrm{~mm})$ 사이의 관계식을 최소자승법으로 추정 하면 이하와 같다.

$$
\begin{aligned}
& C W=1.0771 R L-2.99 \\
& R L=0.8998 C W+5.12 \\
& C L=0.9345 R L-5.61 \\
& R L=1.0334 C L+8.50 \\
& C L=0.8517 C W-1.71 \\
& C W=1.1274 C L+5.20 \\
& B H=0.6209 R L-14.38
\end{aligned}
$$$$
\left(R^{2}=0.9692\right)
$$$$
\left(R^{2}=0.9692\right)
$$$$
\left(R^{2}=0.9657\right)
$$$$
\left(R^{2}=0.9657\right)
$$$$
\left(R^{2}=0.9602\right)
$$$$
\left(R^{2}=0.9602\right)
$$$$
\left(R^{2}=0.8559\right)
$$

회 귀식 의 경우, 반드시 역함수의 관계가 성립 하는 것은 아니므로 회 귀의 역추정을 푀하기 위 하여 체 장 각각에 대 한 회 귀식을 구하여 나타내 었다. 본 연구에서 얻어진 암게의 체 고와 Park et al.(2003)이 구한 수게의 체 고 $(B H=0.3959 R L+$ 0.62)를 비교하면 최대갑장이 큰 범위에서 암게 의 체고가 높다는 것을 알 수 있다. 공분산분석으 로 암수의 최대갑장 - 갑고의 관계식을 비고하여 보면 암수 사이에 차이가 있다는 결과를 나타넨 다. 이것은 암게 의 경우, 갑폭 $80 \mathrm{~mm}$ 정도 에서 성 숙하면 복지 포란하므로 성숙한 암게는 수게에 비하여 체고가 ㄴㅗㅗ아지는 영향으로 생각된다.

대게의 경우, 수게는 탈푀를 반복하여 갑폭 $15 \mathrm{~cm}$ 의 대형 개체로 성장하나, 최근 연구에 의 하면 최종탈피가 존재하며 최종 탈피한 수게의 집게발(chela) 굵기는 최종 탈피하지 않은 개체 에 비하여 상대적 크다고 알려져 있다(Conan and Comeau, 1986; Yamasaki, 1994; Park et al., 2003). 또한, 수게 집게발의 상대적 성장 차이는 성숙을 나타내 는 지 표가 된다. 반면에 암게의 경 우에는 갑폭 $8 \mathrm{~cm}$ 전후에 서 성숙하여 생 애의 최 종탈피 를 행 하고 그 이상 성장하지 않는다 $(\mathrm{Lim}$, 2001). 본 연구에서 얻어진 암게의 갑폭 $(C W)$ 및

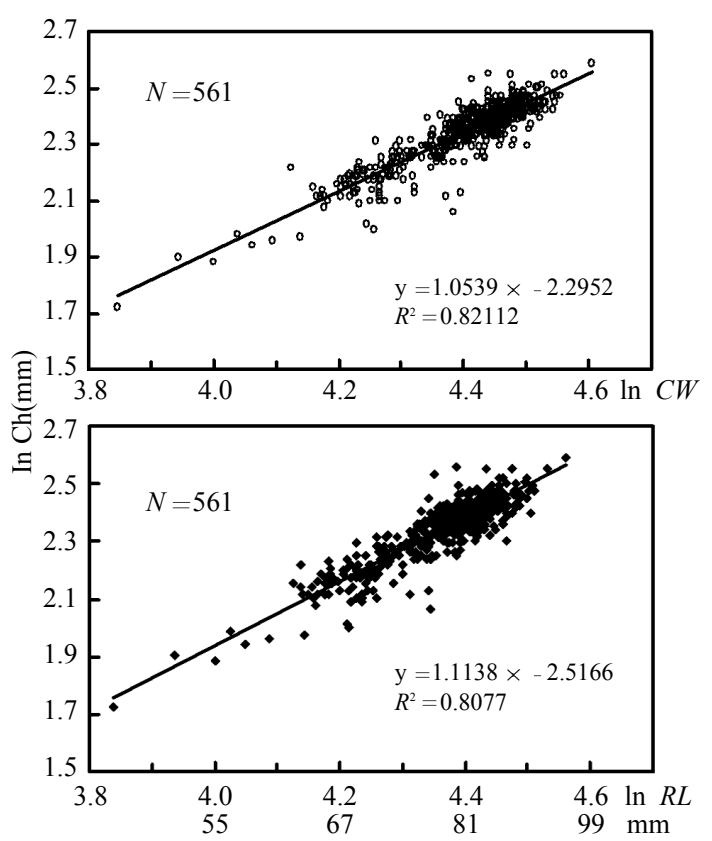

Fig. 1. Relationship between the carapace size and the chela height in the natural logarithm for the female snow crab. $C W$ : carapace width, $R L$ : maximum carapace length (rostral horn), $C h$ : chela height 
최대갑장 $(R L)$ 에 대한 집 게발 높이 $(C h)$ 를 Fig. 1 에 나타내었다. 암게의 경우, 수게의 경 우와는 달리 성장하여 집게발 높이 $(\mathrm{Ch})$ 가 상대적인 성 장 차이를 보이는 그룹이 나타나지 않는다는 것 을 알 수 있다.

\section{체장조성}

시험 어구에 어획된 암게의 최대갑장 $(R L)$ 조
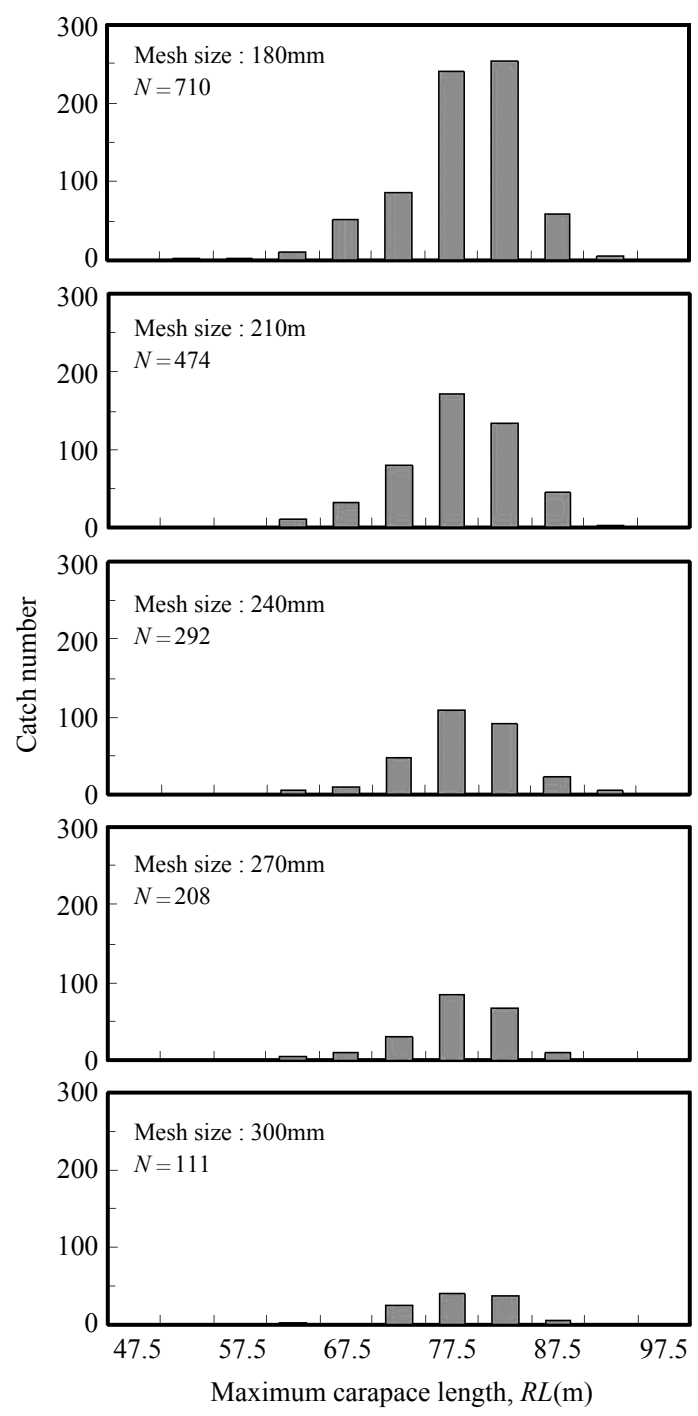

Fig. 2. Maximum carapace length $(R L)$ distributions of female snow crab caught in the experiment.
성을 체장계급 $5 \mathrm{~mm}$ 단위로 구분하여 Fig. 2 에 나타내 었다. 암게의 최대갑장 범 위는 $45-$ $100 \mathrm{~mm}$ 이며 주로 $60-90 \mathrm{~mm}$ 사이에 분포하는 것으로 나타났다. 또한, Fig. 2 로부터 자망의 망 목크기가 증가하면 체 장이 작은 암게의 어획이 감소한다. 동일한 망목크기의 자망에 어획된 수 게(Park et al., 2003)의 체장조성(최대갑장 범위 가 $45-155 \mathrm{~mm}$, 대 다수는 $60-115 \mathrm{~mm}$ 사이에 분 포)과 비교하면 암게는 수게에 비하여 상대적으 로 작다는 것을 알 수 있다 이와같은 결과는 자 망의 망목크기가 증가하면 체 장이 작은 암게의 혼획이 감소하고 선상에서 암게를 선별하여 재 방류하는데 소요되는 노동력을 절감시킬 수 있 다는 것을 의미한다.

시험조업으로부터 얻어진 어획 자료 중에서 어획이 거의 없었던 1 회(수심 $420 \mathrm{~m})$ 의 시험조업 자료를 제외하고 11 회의 어획자료를 활용하여 망목크기별 자망 1 폭당 암게의 평균 어획 개체 수 $c$ 를 계산하면 망목크기가 $180,210,240,270$, $300 \mathrm{~mm}$ 의 경 우, 각각 $16.1,10.8,6.6,4.7,2.5$ 마리 로 나타났으며 이하의 지수함수로 표현된다 (Fig. 3).

$$
c=253.88 \exp (-0.0151 m) \quad\left(R^{2}=0.9922\right)
$$

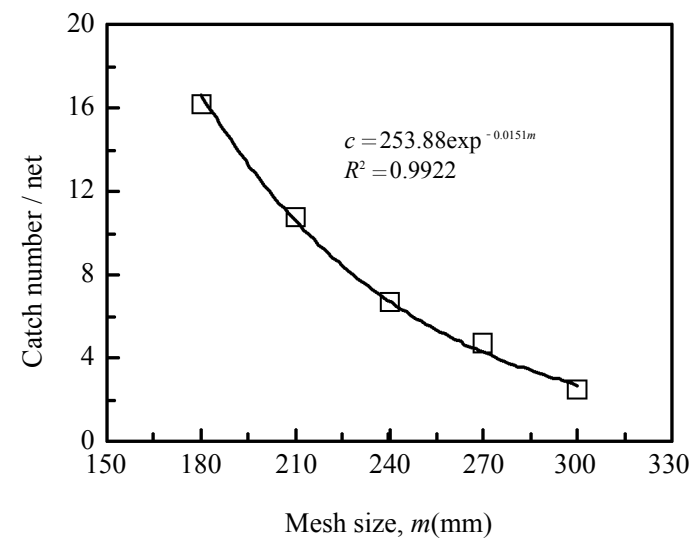

Fig. 3. Relationship between the mesh size $(m)$ and the catch number per unit net of female snow crab (c) caught in the experiment. 
망목 선택성곡선

시험조업에서 얻어진 망목크기별 암게의 체 장조성 자료를 사용하여 Kitahara 방법(Kitahara, 1968) 에 의한 망목선 택성 곡선 파라미터를 추정 하였다. 선택성 곡선을 나타내는 지수 함수는 자 망에서 많이 사용하는 좌우비대 칭형(3 차식)으 로 가정하였다. 추정된 망목선택성 Master 곡선 은 Fig. 4 와 같으며 이 하의 수식으로 표현된 다.

$$
\begin{aligned}
S(R) & =S(R L / m) \\
= & \exp \left\{\left(44.121 R^{3}-83.965 R^{2}+52.591 R\right.\right. \\
& \quad-5.000)-5.868\}
\end{aligned}
$$

망목선 택성 곡선(Fig. 4)으로부터 $R L / m$ 이 증 가함에 따라 선택률은 0 에서 1 까지 변화하며 선 택률 1 을 나타내는 $R L / m=0.563$ 이상의 범위에서 는 관측치가 없어 선택률의 추정이 어렵다. 어류 를 대상으로 하는 자망(Cho et al., 2000: Park et al., 2004)의 경우, 일반적으로 종형(Bell Type)의 망목 선택성 곡선을 나타내는데 비하여 본 연구에서 얻어진 암게 의 망목선택성 곡선 은 Sigmoid 형태 에 가까운 망목선택성 곡선을 나타내고 있다. 이 와 같은 결과는 갑각류인 대게 의 경우, 그물에 꽂 혀서 어획되는 어류와는 달리 얽혀서 어획되는 영향으로 생각된다(Fujimori et al. 1996; Park et al., 2003). 금후, 얽혀서 어획 되는 갑각류의 망목선택 성에 대하여 보다 많은 연구가 필요하다.

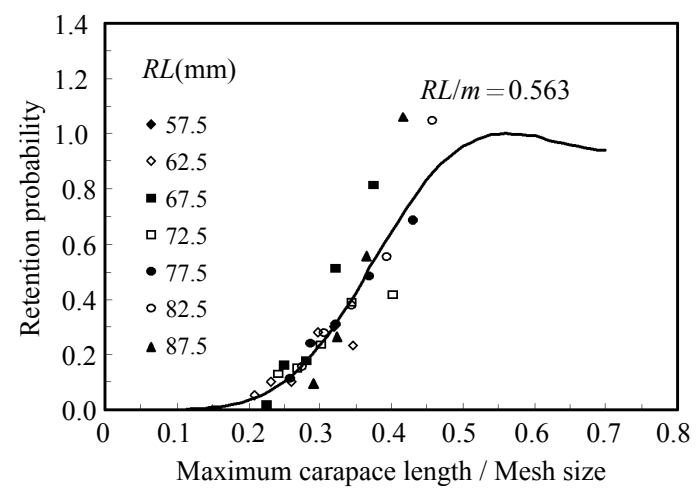

Fig. 4. Master selection curve of gill net for female snow crab.
자망에 대한 암게의 망목선택성 곡선(Fig. 4) 으로부터 선 택률 $0.1,0.2,0.3,0.4,0.5$ 를 나타내 는 $R L / m$ 의 값은 각각 $0.249,0.290,0.319,0.344$, 0.367 이다. 본 연구에서 추정된 암게의 망목선택 성 꼭선과 Park et al.(2003)이 추정한 수게의 망 목선택성 곡선을 비교하여 보면 암게의 망목선 택성 곡선이 약간오른쪽에 위치하는 것을 알 수 있다. 망목크기 $240 \mathrm{~mm}$ 인 자망을 가정하여 선택 률 0.5 인 수게와 암게의 최 대갑장을 계 산하여 보 면 각각 85 및 $88 \mathrm{~mm}$ 이 며 선 택률 1.0 에 해 당하는 수게와 암게의 최대갑장은 각각 132 및 $135 \mathrm{~mm}$ 를 나타낸다: 이와 같은 결 과로 부터 동일한 선택 률을 나타내는 수게의 최대갑장이 암게에 비하 여 다소 작다는 것을 알 수 있다. 이것은 최대갑 장이 동일할 경우, 수게가 암게보다자망 어구에 어획될 확률이 높다는 것을 의 미한다.

생물의 암수에 따른 망목선택성 의 차이 는 자망 에 어획되는 암수의 체장 조성에 차이가 있는 도 루묵 자망에서도 나타나 있다(Jeong et al., 2009). 금후, 암수의 체장 차이 또는 행동 특성 과 망목선 택성 과의 관련성에 대한 보다 많은 연구를 통하 여 이와 같은 현상에 대한 구명이 필요하다.

\section{결 론}

대게 자원의 지속적 이용을 위해서는 재생산 에 기여하는 암게의 혼획을 감소시키고 상품성 있는 수게를 선택적으로 어획하는 것이 중요하 다. 자망에 대한 대게 암컷 의 망목선택성을 구명 하기 위하여 망목크기 가 $180,210,240,270$ 및 $300 \mathrm{~mm}$ 인 5 종의 대게 자망을 제작하여 2002 년 1 월부터 2003 년 3 월까지 동해 안 죽변 연안에서 시 험 조업을 수행하고 망목크기별 어획물 종류 및 개체 수를 조사하였으며 대게 의 갑폭 $C W$, 최대갑 장 $R L$, 체중 $B W$ 등을 측정 하였다. 시험조업에서 얻어진 어획 물의 $97 \%$ 가 대게 로 나타났으므로 대 게 자망의 어종선택성 은 매우 높은 것으로 판단 되었다. 자망에 대한 암게 의 망목선택성 곡선 추 정은 Kitahara 방법 을 적용하여 해석하였으며 망 
목크기가 증가할수록 소형 개체 의 어획이 감소 하는 것으로 나타났다. 그리고 선택 률 1 을 나타 내는 $R L / m$ 의 값은 0.563 이었으며 선택률이 0.1 , $0.2,0.3,0.4,0.5$ 를 나타내는 $R L / m$ 의 값은 각각 $0.249,0.290,0.319,0.344,0.367$ 으로 추정되었다. 본 연구 결과를 Park et al.(2003)이 추정한 수게 의 망목선택 성 곡선과 비교하여 보면 동일한 선택 률을 나타내는 수게 의 최대갑장이 암게 에 비하 여 다소 작다는 것을 알 수 있다. 또한, 암수의 최 대갑장이 동일할 경우에는 수게 가 암게보다 자 망 어구에 어획 될 확률이 높은 것으로 나타났다. 이와 같은 결과는 대게 암수의 체장조성 또는 형 태적 차이 등에 의한 영향으로 생각되며 금후 이 들 영향에 대한 추가적인 연구 수행이 필요하다.

\section{사 사}

본 연구는 국립수산과학원(자원관리형 자망, 통발 어 구어 법 기 술개 발, RP - 2008 - FE - 005) 의 지원에 의해 수행되었습니다.

\section{참고문헌}

Cho, Y.B., C.D. Park and J.H. Lee, 2000. A study on the selectivity of the mesh size in trammel net for Cynoglossidae Spp. Bull. Korean Soc. Fish. Tech., 36(2), $89-95$.

Conan, G.Y. and M. Comeau, 1986. Functional maturity and terminal molt of male snow crab, Chionoecetes opilio. Can. J. Fish. Aquat. Sci., 43, 1710 - 1719.

FAO, 1992. Introduction to tropical fish stock assesment. FAO Fisheries Technical Paper, 306/1, 172 - 199.

Fujimori, Y., T. Tokai, S. Hiyama and K. Matuda, 1996. Selectivity and gear efficiency of trammel nets for kuruma prawn (Penaeus japonicus). Fisheries Research, 26, 113 - 124.

Ishida, T., 1962. On the gill net mesh selectivity curve. Bull. Hokkaido Reg. Fish. Res. Lab., 25, 20 - 25.

Jadamec, LS., WE. Donaldson and P. Cullenberg, 1999. Biological field techniques for Chionoecetes Crabs. University of Alaska Sea Grant College Program, pp
$29-31$.

Jeong, E.C, H.H. Park, B.S. Bae, D.S. Chang, C.S. Kim, S.H. Choi and H.K. Cha, 2009. Size selectivity of gill net for male Japanese sandfish (Arctoscopus japonicus) off Gangwon in winter. J. Kor. Fish. Soc., 42(1), $78-82$.

Kitahara, T., 1968. Mesh selectivity curve of sweeping trammel net for branquillos. Bulletin of the Japan. Soc. of Scientific Fisheries, 34(9), 759 - 763.

Lim, Y.S., 2001. Sexual maturation and larval growth of the snow crab, Chionoecetes opilio. Pukyong National University, Doctoral Thesis, pp 1 - 114.

Millar, R.B and S.J. Walsh, 1992. Analysis of trawl selectivity studies with an application to trouser trawls. Fisheries Research, 13, 205 - 220.

Miyake, S., 1983. Japanese Crustacean Decapods and Stomatopods in Color. Vol. II. Hoikusha, Tokyo. pp $31-32$.

Park, C.D., H.C. An, S.K. Cho and C.I. Baik, 2003. Size selectivity of gill net for male snow crab, Chionoecetes opilio. Bull. Korean Soc. Fish. Tech., 39(2), $143-151$.

Park, C.D., E.C. Jeong, J.K. Shin, H.C. An and Y. Fujimori, 2004. Mesh selectivity of encircling gill net for gizzard shad Konosirus punctatus in the coastal sea of Korea. Fish. Sci., 70, 553 - 560.

$\mathrm{Xu}, \mathrm{X}$. and R.B. Millar, 1993. Estimation of trap selectivity for male snow crab (Chionoecetes opilio) using the SELECT modeling approach with unequal sampling effort. Can. J. Fish. Aquat. Sci. 50(11), $2458-2490$.

Yamasaki, A., 1994. Studies on stock management of snow crab based on biology. Kyoto Institute of Oceanic and Fishery Science, Special Report, No.4, pp $1-53$.

2008 년 10 월 10 일 접수

2009 년 3 월 30 일 1 차 수정

2009년 5월 19일 수리 